\title{
ISABEL PONE EN CARTAS SUS RECLAMOS: MAESTRAS Y EPISTOLARIOS. ROSARIO, ARGENTINA (1875 - 1879)
}

\author{
Isabel puts in letters their claims: Teachers and epistolarios. \\ Rosario, Argentina (1875 - 1879)
}

http://dx.doi.org/10.22235/pe.v9i2.1300

\section{MICAELA PELLEGRINI MALPIEDI}

Recibido: 13-04-2016

Revisado: 06-05-2016

Aceptado: 22-05-2016

Resumen: El presente artículo posee dos objetivos que articulan tres palabras clave: escuela normal, maestra y epistolario. El primer cometido se compromete a pensar cómo el surgimiento del sistema educativo argentino operó sobre la participación de las mujeres decimonónicas (maestras) en las prácticas educativas. En Argentina, a fines del siglo XIX, el Estado pensó en la figura femenina como la más apta para llevar a cabo el acto civilizador de la escuela normal; dicha finalidad estaba justificada por sus "dotes naturales": cuidado y predisposición hacia los otros. Ahora bien, en un segundo objetivo, se recapitaliza esta cuestión para pensar cómo esta misma prescripción fue reformulada por las propias mujeres para salir del espacio privado doméstico y entablar relaciones y negociaciones en los espacios propios de lo masculino y de los masculinos.

\footnotetext{
* Licenciada y Profesora en Ciencias de la Educación por la Facultad de Humanidades y Artes de la Universidad Nacional de Rosario (Argentina). Actualmente reviste como becaria doctoral del Consejo Nacional de Investigaciones Científicas y Tecnológicas (CONICET). Está realizando un Doctorado en Ciencias de la Educación en la Facultad de Filosofía y Letras de la Universidad de Buenos Aires. Su línea de investigación es la historia sociocultural, de las mujeres y de la educación.
} 
Isabel pone en cartas sus reclamos: Maestras y epistolarios. Rosario, Argentina (1875 - 1879)

Indagar sobre la capacidad de reclamo que estas mujeres del magisterio poseen para peticionar sobre aquello que consideran justo $y$, con ello mismo, su capacidad de desafiar los discursos esencialistas sobre "maestras" que circulaban en la época. Para ello, se analizarán las cartas escritas por una joven docente: Isabel Coolidge.

Palabras clave: Escuela normal, maestras, epistolario

\begin{abstract}
The present work aims to analyze two topics around three words: school, teacher and letter. The first commitment is compromised to think how the rise of Argentine Educative System operated over the female teachers' participation in the educational practices. At the end of the nineteenth century, the Argentine Estate considered that the female figure was the most suitable to drive the civilizing act of the normal school. These beliefs were justified by her "natural gifts": care and predisposition towards others. In a second commitment, we extrapolate this question to reflect how this prescription was reformulated by the own women to escape from the private domestic space in order to establish new relationships and negotiations in spaces which belonged to male (public) and males (institutions and ministry agents). Investigate the ability of these women claim that the teachers have to petition on what they consider fair and thus himself, his ability to challenge the essentialist discourses on "teacher" that circulated at the time. This life experience will be analyzed from letters written by a young foreign teacher: Isabel Coolidge.
\end{abstract}

Keywords: School, normal education, teachers - letters

\title{
INTRODUCCIÓN
}

El presente escrito recorta su línea de reflexión de una temática general: las primeras experiencias de formación de los maestros y maestras en Argentina. Así, se detendrá en un caso particular: el Colegio Normal N.. 1 -la primera escuela formadora de maestras (mujeres) de la ciudad de Rosario ${ }^{1}$, para analizar las

\footnotetext{
${ }^{1}$ La ciudad de Rosario está ubicada en el centro-este, en la provincia de Santa Fe, Argentina. Es la tercera ciudad más poblada del país, después de Buenos Aires y Córdoba, y constituye un importante centro cultural, económico, educativo, financiero y de entretenimiento. Forma parte del denominado Triángulo Agrario, junto con las localidades de Pergamino y Venado Tuerto. Está situada sobre la margen occidental del río Paraná, en la Hidrovía Paraná - Paraguay.
}

Revista Páginas de Educación. Vol. 9, Núm. 2 (2016) ISSN: 1688-5287; e-ISSN: 1688-7468 
marcas escritas que dejó su primera directora: Isabel B. Coolidge. Esas marcas no son muchas, pero sí las suficientes para facilitar el trazado de una hipótesis. Esta es: si bien las mujeres fueron elegidas para el ejercicio del magisterio porque se las estimó naturalmente altruistas, angeladas, dadoras y guardianas, las prácticas nos devuelven una imagen diferente, en la que se las ve peticionando, luchando por sus derechos, por ejemplo, el salario. Las cartas de la primera directora del Normal $\mathrm{N} . .1$ dan cuenta de ello, pero también dan cuenta de cómo se expresa y negocia con los varones del sistema. La experiencia de Isabel es una entre tantas, pero aquí se la toma porque fue la primera mujer que ejerció como directora de un curso formador de mujeres maestras en la ciudad de Rosario.

El Normal N. 1 Dr. Nicolás Avellaneda fue creado en 1879 y comenzó a funcionar como un anexo del por entonces prestigioso Colegio Nacional N. 1. El Nacional era una escuela de varones, y su director, Enrique Corona Martínez ${ }^{2}$, tuvo a bien pensar en la educación de las mujeres. Motivado por esta preocupación, comenzó las tratativas para abrir un curso destinado a ellas. De estas negociaciones surgió el Normal $N . .91$, cuya primera directora fue Isabel Coolidge, una de las maestras estadounidenses traídas por el proyecto sarmientino.

Si bien mucho se habló de la llegada al país de estas mujeres, de algunas de ellas se han borrado sus marcas, especialmente en la ciudad de Rosario. Poco se sabe de Isabel; algunas huellas quedaron en el Libro de Oro de la escuela Normal y, afortunadamente, en el archivo del Nacional № 1. En este archivo se encontraron 15 cartas escritas por la maestra.

¿Por qué este trabajo se detiene exclusivamente en las cartas? Por un lado, porque son las huellas con las que se cuenta, pero por otro para ponderar el valor

\footnotetext{
${ }^{2}$ Según Colovini y Carvalho (2002) en 1874, días antes del ciclo lectivo fundacional, se nombra al primer rector: Enrique Corona Martínez, bajo cuya rectoría el Nacional adquiere un desarrollo constante. Crece como institución, pero además proyecta otras. Así incorpora a su establecimiento la primera Escuela de Derecho de Rosario, la Escuela de Comercio, la de Artes y Oficios y la primera Escuela Normal, liderada por maestras norteamericanas.
} 
que los epistolarios han adquirido para dar luz a temas y objetos antes no contemplados. Es decir, si bien las cartas oficiales (esas con membretes, con libro copiador y sellos) eran utilizadas, las otras (las de carácter íntimo), fueron rápidamente desechadas, fundamentalmente, por las dificultades de datar su procedencia. Empero, en las últimas décadas esto ha cambiado en función de otorgar voz a nuevos agentes históricos. Si bien las maestras traídas por Domingo Faustino Sarmiento quedaron rápidamente registradas en la historiografía de la educación argentina, por lo cual no son personajes anónimos, no todas fueron recuperadas con la misma impronta. Rescatar la correspondencia permite trabajar entre lo íntimo (del acto de escribir y de los trazos) y lo público (la nota a las autoridades). Isabel escribe cartas a funcionarios del sistema educativo. Sigue las reglas del género epistolar y las capitaliza para poner por escrito sus preocupaciones. Estas serán las que se tomen para interrogar concepciones y modos en que se dieron los primeros pasos en la institucionalización de la escuela pública.

\section{La escuela, el proyecto normalista y las maestras}

Desde los orígenes del Estado Nacional se pensaron las claves para dar forma al sistema educativo argentino. Un varón protagonista de este proceso fue, sin dudas, Sarmiento. Estando exiliado en Chile, investigó, imaginó, viajó y escribió, buscando crear las formas para erradicar de la Argentina el carácter bárbaro que la atravesaba. Así, en uno de sus tantos viajes, conoció Estados Unidos y lo eligió como modelo a partir del cual perfeccionar la economía y la sociedad nacional en vista al progreso (civilizado y capitalista). Entre los distintos aspectos que Sarmiento aprendió a admirar del país del norte, las formas de educar fueron relevantes. Educar al soberano era el secreto de la civilización, por lo que el Estado debía ser el impulsor de la educación popular, y formar principalmente a los ciudadanos (Sarmiento, 2001). En las escuelas estadounidenses había una marcada participación femenina, como estudiantes, pero también como 
educadoras. En consecuencia, educación popular y maestras a cargo de la transmisión de las primeras letras fueron algunos de los rasgos que marcaron el proyecto impulsado por Sarmiento durante su presidencia (1868 a 1874). Así, las mujeres comenzaron a entrar al mundo de las instituciones educativas públicas.

$\mathrm{Si}$ hasta el momento los varones habían sido quienes ejercían mayoritariamente la enseñanza de las primeras letras (fines del siglo XVIII y mediados del XIX), a partir del modelo sarmientino las mujeres ingresaron al universo de la docencia con fundamento político y teórico. Su incorporación fue justificada bajo argumentos. El primero partía de reconocer a la maternidad y a la propensión de cuidar a los otros como parte de la esencia femenina y, por ende, como una actitud natural para la educación de la primera infancia. Ahora bien, el segundo, se relaciona principalmente con cuestiones de salario: a las féminas se les paga menos. Sarmiento pensó a la mujer en términos económicos, al ofrecerles por su trabajo una suma menor que la pretendida por los varones. Al reconocer como condición femenina a la mujer doméstica, que además de ser madre, abnegada y custodia de la infancia era más barata (porque siempre tenía cerca un varón dador de recursos), se tornó el sujeto ideal para educar en las escuelas. (Morgade, 1997; Yannoulas, 1996).

Si bien en el centro urbano del país las mujeres ocuparon en mayoría el rol de maestra normal, los varones fueron quienes constituyeron la esfera de los cargos superiores del sistema educativo. Estos, además, tuvieron exclusividad en los trabajos docentes alejados de las grandes ciudades. En este caso $-\mathrm{y}$ debido a las características adversas de la geografía alejada del centro del país - los mismos dotes femeninos utilizados como pretexto para el desempeño de la mujer en la docencia, fueron usados como negativos: por ejemplo, su debilidad y decoro. (Fernández y Caldo, 2013).

Las Escuelas Normales permitieron que las mujeres estudiaran, lo que dio lugar al famoso proceso de feminización de la docencia (Morgade, 1997; Yannoulas, 1996). Muchos fueron los debates que gravitaron para pensar si era 
pertinente o no dejar que ellas educaran en las escuelas, pero se impuso la tendencia a aceptar la participación femenina en el ejercicio de la docencia. Esta aceptación fue parte del juego pendular de inclusión y exclusión que marca el paso de las mujeres por la historia (Barrancos, 2001). Esto es, si por un lado se las dejó participar, fue en función de considerar el oficio docente afín con la naturaleza doméstica de las mujeres. Más allá de esta justificación, la posibilidad de estudiar, de salir del hogar paterno, de trabajar, de reunirse con otras mujeres fuera de la casa, de percibir un salario, de tener acceso a los recursos de la cultura, fueron llaves de apertura al espacio público, de generación de saberes y de elaboración de reclamos.

\section{La Escuela Normal y sus maestras llegan a Rosario}

El Normal N. 1 , escenario de ejercicio de la docencia de la mujer protagonista de estas páginas, fue la primera escuela de estas características en la provincia de Santa Fe. Esta institución lleva el nombre de Nicolás Avellaneda porque fue quien, primero como ministro de instrucción pública de Sarmiento y luego como presidente de la Nación, trabajó para formalizar la formación docente de maestros nacionales. Fue así que, en 1875, sancionó un decreto que establecía la apertura de Escuelas Normales en cada capital de provincia. Empero, en la provincia de Santa $\mathrm{Fe}$, aquel decreto tuvo una connotación especial y la escuela no abrió en la capital, sino en la ciudad de Rosario. Una ciudad que, si bien no era administrativa ni patricia, se destacaba por la proyección liberal y comercial de sus integrantes (inmigrantes europeos italianos y españoles, entre otros). En realidad, lo que sería luego el primer Normal de la provincia empezó funcionando como un curso para maestras anexo al Colegio Nacional N. 1, durante el año 1879. Fueron las tratativas del director del Nacional, Enrique Corona Martínez, las que posibilitaron la apertura del curso (Carvalho y Colovini, 2002), que fue dirigido por Isabel B. Coolidge. Isabel había sido traída por Sarmiento para que ejerciera como docente en el departamento de aplicación de un curso para maestras de la ciudad de 
Concepción del Uruguay (Entre Ríos), pero luego fue contratada para cumplir otra función: dirigir el Normal de Rosario.

De acuerdo al Registro Nacional (1877), la docente firmó su primer contrato con el Ministerio de Instrucción Pública, por el cual se compromete a ejercer, durante tres años, como maestra de Escuela Normal u otra escuela designada. En ese contrato se especifica el sueldo que percibiría a razón de su trabajo, y también se detalla sobre el pago de los gastos que se originarían por su traslado desde Estados Unidos hasta la provincia de Buenos Aires, y luego, hasta el pueblo o ciudad en que se le encomendara ejercer la docencia. El documento dejaba establecido que los gastos serían solventados por el propio Ministerio de Instrucción Pública:

\section{Contrato celebrado entre la Maestra Normal Isabel B. Coolidge y el Ministro Plenipotenciario de la República Argentina, Doctor Manuel R. García}

Nueva-York, Marzo, 19 de 1877.-

Por medio del presente, queda convenido y contratado entre el Ministerio de la República Argentina, en representación del Ministerio de Instrucción Pública, de la misma, é Isabel B. Coolidge conviene en entrar al servicio de la República Argentina como Maestra en la Escuela Normal o Escuela para que sea designada por el Ministerio de Instrucción Pública, por el período de tres años a contar desde la fecha de su embarque en Nueva-York. El sueldo será de mil doscientos pesos fuertes anuales (1200) en oro o su equivalente en cantidades de a cien pesos fuertes (100). La suma de trecientos pesos fuertes en oro, le será abonado en Nueva-York, para cubrir los gastos del pasaje desde Estados Unidos hasta Buenos Aires- el gasto del viajes desde Buenos Aires hasta el pueblo o ciudad del interior donde esté situada la escuela, será abonada por el Ministerio de Instrucción Pública- cuando este contrato esté terminado, ya sea por espiración del tiempo, o mutuo convenio, o por causa suficientemente legal, 
el Ministerio de Instrucción Pública pagará a la referida Isabel B. Coolidge, una suma igual al costo de un pasaje de primera clase de vuelta a NuevaYork.

- Firmados - Manuel R. García. - Isabel B. Coolidge. - Testigo - Eduardo F. Dacison Cónsul General (Registro Nacional, 1877).

Pese a la importancia de esta maestra, las huellas que dejó no son muchas, pero sí las suficientes para reconstruir algunas de las dificultades que las mujeres hallaron a la hora de ejercer el magisterio en estas latitudes. Como ya fue dicho, Coolidge dejó una serie de cartas que se podrían calificar como formales o administrativas. Es Michel de Certeau (1974) quien ayuda a pensar el análisis epistolar como un medio para trabajar en este sentido. Con el concepto de límites, este historiador se refiere a los desvíos, los préstamos, los desplazamientos, las formas de mestizaje. De Certeau revaloriza el uso de las cartas como fuentes para historiar sobre las sensibilidades cotidianas que se pueden hallar en las huellas, marcas silenciosas dejadas por sujetos que se han mantenido en los márgenes del accionar político y publico del país. De este modo, "la gente común" "las personas sin historia", "los de abajo" (Guha, 2002) ya sea desde el anonimato o no, también hicieron historia. Las mujeres en general, e Isabel B. Coolidge en particular, son un ejemplo de ello. Es en esta clave que se piensa la escritura epistolar de Isabel. Escuela, mujer-maestra y carta se relacionan para comprender su paso como la primera directora de la primera Escuela Normal de Rosario.

\section{Isabel, una maestra que reclama}

Isabel B. Collidge fue una maestra normal de una escuela pública, con los significantes que ello tiene. A fines del siglo XIX, el normalismo se constituyó en Argentina como la forma escolar capaz de otorgar títulos oficiales para el ejercicio del magisterio. Fue el modelo pedagógico que prescribió, además de los 
contenidos a enseñar, la forma de intervención sobre los aprendizajes de los alumnos. Las maestras del Normal se caracterizaban por su obediencia, su dedicación desinteresada, su vocación y respeto hacia las autoridades: se convirtieron en el ejemplo a seguir de las generaciones más jóvenes y, como tal, debían respetar el orden instaurador.

La tarea de la enseñanza quedó investida con carácter apostólico, y en este marco comenzó a pensarse como una actividad que solo se bastaba con los beneficios simbólicos y del reconocimiento social. La docencia fue fundamentada en la clave de la vocación y no del oficio o de la profesión, por lo cual todas las discusiones en cuanto a retribución monetaria quedaban canceladas. En otras palabras, lo que se hace por devoción y entrega, como parte de una religión civil, clausura cualquier búsqueda de lo material ${ }^{3}$. Sin embargo, en aquellos mismos años:

Las voces del magisterio levantaron las banderas de un movimiento que reclamó el reconocimiento de su formación profesional, mejores condiciones de trabajo y una remuneración acorde con la misión política que debían llevar adelante. Reclamaron aquello que las propias autoridades políticas se encargaron de difundir a la hora de promover la profesionalización del magisterio (Lionetti, 2007, p. 9).

Lionetti (2007) considera que las docentes experimentaron rápidamente sensaciones de fracaso o éxito. Si bien algunas alcanzaron el prestigio pedagógico y social que les había prometido la Escuela Normal, hubo una mayoría de maestras que quedaron en el olvido, y que compartían el desencanto por la diferencia entre lo que creían merecer y lo que realmente recibieron. Isabel B. Coolidge se encontraba entre estas, y sus cartas lo corroboran. En ellas se puede

\footnotetext{
${ }^{3}$ Lucía Lionetti (2007) cita que la metáfora el "sacerdocio de los tiempos modernos" se debe en verdad al pensamiento pedagógico que circuló en Europa durante el siglo XVIII. Esta analogía de la docencia con la función clerical se debe a la figura de un varón que tenía como función social civilizar; era un ser despojado de recursos y que significaba un ejemplo para el resto de la comunidad.
} 
leer la diferencia infranqueable entre aquello que el discurso oficial le habría prometido y lo efectivamente conseguido (de ahí el reclamo). Estas diferencias no solo restaban en cuestiones sociales y de reconocimiento profesional, sino también en cuestiones relacionadas con las condiciones y las remuneraciones de trabajo.

A Isabel, en su contrato originario acordado con el Ministerio encargado de la educación, le habían prometido el pago de los traslados, viáticos y estadía correspondientes a su viaje desde el norte de América al sur del continente. Esto no solo no fue concretado (la joven docente tuvo que enfrentar dichos gastos) sino que, en la lista de deudas, también se enumeran meses de salarios no abonados. Por ello, esta maestra decide romper con el imaginario social de obediencia, docilidad y sacerdocio que se le atribuía a las normalistas, y exigir la paga que le correspondía.

El modo que encontró para reclamar sobre su salario a las autoridades institucionales y ministeriales fue la escritura de cartas:

Rosario, Octubre 25 de 1879

Extremo Sr. Ministro de Justicia, Culto e Instrucción Pública, Dr. Don Miguel Goyena:

Ext. Sr.:

Cuando en febrero pasado fui nombrada como Directora de la Escuela Normal anexa al Colegio Nacional de esta ciudad, hice los gastos de viaje de mi cuenta, y en oportunidad reclamé su importe de ese Ministerio, sin que hasta la fecha se me hayan abonado, lo que ruego a V.E. se sirva ordenar.

Además, con fecha 10 de julio la Aduana de esta ciudad suspendió mi sueldo por haber sido nombrada otra persona que me sustituyera durante una licencia pedida por enfermedad, lo que participo al Sr. Ministro, 
pues teniendo contacto y encontrándome de nuevo en el cumplimiento de mi cargo, necesito me sean pagados dichos sueldos para cubrir mis necesidades.

Saludo con todo respeto.

Al Sr. Ministro.

Isabel B. Coolidge (1879).

Las huellas de Isabel B. Coolidge encontradas en esta carta resultan de una gran riqueza, por dos motivos. El primero, porque demuestra que efectivamente las mujeres fueron elegidas como maestras por razones económicas: al no ser sustento de hogar, los salarios podían ser no solo más bajos sino demorados e incluso nunca pagados. Pero, el segundo, pone al desnudo la capacidad de reclamo y negociación de Isabel: las mujeres no se callaron, sino que reclamaron todo lo necesario. Frente a esta cuestión, resulta interesante trabajar con el concepto de configuración, de Rockwell (1997). Esta intelectual coloca el énfasis en las prácticas cotidianas de los actores educativos (docentes, alumnos, alumnas, padres de familia...) y sus vínculos con las instituciones escolares, el poder local, etc., como así aquellos sujetos que han quedado por fuera de los márgenes educacionales. De esta manera, la configuración permite pensar a la Escuela Normal como un lugar flexible, en el cual también tenían voz los sujetos particulares, sujetos que, más allá de la prescripción de la norma, sabían ejercer un margen de maniobras (Lionetti, 2007). Sujetos que en la actualidad han pasado al olvido, pero que han tenido sus participaciones singulares en la organización de las Escuelas Normales.

\section{Isabel, una maestra que escribe cartas}

Isabel fue una maestra que eligió la correspondencia como vía de comunicación con autoridades de la Escuela Pública y del Ministerio. Esta elección no es casual. De acuerdo a Sarah C. Chambers (2005), la escritura epistolar significó para las 
mujeres del siglo XIX el modo de expresión por excelencia. De acuerdo con esta afirmación, la historiadora considera que las mujeres de aquella época "pensaban, pero las callaban"4 (p. 3 ) y es por eso que las cartas se constituyeron en el medio desde el cual el género femenino se expresó, corrompió el silencio, la represión y la domesticidad propia del siglo XIX (Castillo Gómez, 2005). Siguiendo con esta posibilidad de época, Isabel B. Coolidge también escribió; aunque en las cartas encontradas no se ve a una mujer sino a una mujer maestra. Es esta condición la que permite que sus cartas sean documentos públicos, formales, donde el contenido puesto en juego reclama e interviene en asuntos de políticas educativas, laborales, etc. Durante el 1800 ha sido la relación mujer-carta la que generalmente se ha manifestado como propia de la intimidad (esfera privada), pero en el caso de esta maestra, es lo público lo que se posiciona como espacio propio.

Resulta interesante pensar este último enunciado desde las ideas de Nancy Fraser, quien busca romper con el pensamiento dicotómico. Fraser (1993) propone considerar a "lo público desde la multiplicidad, permitiendo la inclusión de intereses y temas que la ideología masculinista burguesa ha etiquetado como 'privados' y que ha manejado como inadmisibles" (p. 58). Así, rompiendo esta partición de lo social, el epistolario de Isabel contiene la formalidad y el protocolo propio de lo masculino, y a la vez se entrecruza con aspectos propios de 10 femenino, como lo es la escritura de una mujer-maestra.

Escuela Normal, Rosario 25 de Mayo

\footnotetext{
${ }^{4}$ La autora considera: “El género de la carta, además, cae en un término medio entre las esferas pública y privada, cuestionando una división estricta entre lo político/masculino y lo doméstico/femenino. La conversación y la correspondencia integraron a las mujeres en las comunidades nacionales emergentes de Europa y las Américas durante el final del siglo XVIII y principios del XIX, y les ofreció una forma de actuar políticamente. Tristemente, la correspondencia femenina no fue recogida y protegida por los primeros archiveros, y aún más, no sólo está perdida la mayor parte sino muy probablemente destruida" (Chambers, 2005, p. 3).
} 
Señor E.C. Martínez, Muy Señor Mío:

Leyendo la carta que usted tiene la bondad de traer del Ministerio de Instrucción para mí. El (sic) dice nada de lo que falta de mi salario para el mes de Abril. Sí, habla de mis gastos a venir desde Concepción.

¿Cómo amigo quiere Ud. decirme que otra cosa tengo que hacer para cobrarlo?

Escribiendo con mucha (...)

Saludo a Ud.

Con toda estimación.

Isabel B. Coolidge (1875, 25 de mayo).

Rosario 10 de junio de 1875

Al Señor Rector del Colegio Nacional y Director de la Escuela Normal.

Encontrándome gravemente enferma y necesitando para mejorar un cambio de clima, ruego a $\mathrm{V}$. se sirva acordarme cuatro meses de licencia para poder atender al establecimiento de mi quebrantada salud.

El favor que espero merecer de los bondadosos sentimientos que emanan al Sr. Rector.

$\mathrm{Su}(\ldots)$

Isabel. B. Coolidge (1875, 10 de junio).

Desde un primer análisis de estas últimas cartas, es posible observar los distintos posicionamientos y lugares que pueden corresponder a las mujeres y los varones pertenecientes a los primeros años de la escuela pública. Entrecruzada con aspectos íntimos, desde las cartas se puede notar la Isabel maestra, que lidia con el poder y la esfera de lo masculino-político. Es cierto que en ambas lo que prevalece son las cuestiones formales y protocolares, al tener como receptor a una autoridad pública; no obstante, en las epístolas Isabel desnuda su lado 
femenino y escribe desde lo privado. Rasgos importantes de este posicionamiento se vislumbran al llamar a Corona Martínez "amigo": “¿Cómo amigo quiere Ud. decirme que otra cosa tengo que hacer para cobrarlo". Asimismo, demuestra su lado más sensible y vulnerable, aspectos importantes que no resultan extraños ante la situación a la que esta joven maestra se encontraba expuesta (una mujer joven, extranjera, en un país muy diferente al propio y en situación de reclamo por un contrato no cumplido): "espero merecer de los bondadosos sentimientos que emanan al Sr. Rector".

Un segundo análisis de la escritura epistolar de Isabel B. Coolidge también permite pensar en las relaciones y las posiciones sociales que toman partido entre los integrantes de la escuela pública analizada. Sirven aquí en dos conceptos propuestos por De Certeau (2000): táctica y estrategia. En este caso, se puede observar que Isabel utiliza las cartas como una táctica: la maestra, para valerse del diálogo con varones, utiliza la escritura epistolar como un medio para vincularse con sujetos y espacios jerárquicos del sistema educativo no accesibles para las mujeres de aquella época. De acuerdo a De Certeau (2000), el laboratorio de la escritura tiene una función estratégica, en tanto hay allí una información que ha sido "recopilada, clasificada, imbricada en un sistema, y de ese modo transformada" (p. 188). De esta manera, quienes no cuentan con un lugar propio entran en juego con los signos de pasividad y a la vez con la posesión de poder para fabricar objetos e interactuar con el medio y transformarlo. Es por esto que las cartas ocupan un lugar importante en la vida escolar de Isabel: al reclamar por el pago de su salario desde estas, logra operar de un modo diferente a los supuestos de pasividad y disciplina. Desde las epístolas, esta maestra se relaciona con sujetos educativos jerárquicamente superiores, al tiempo que se ubica en espacios propios de las esferas masculinas.

\section{REFLEXIONES FINALES}


El presente trabajo ha tenido por finalidad repensar y poner en discusión una tensión acaecida por la escuela pública argentina: salario docente y mujer-madremaestra. Se intentó demostrar cómo las políticas educativas de fines del siglo XIX pensaron a las mujeres como propias de una naturaleza femenina que las convertía en las más aptas para solventar una educación popular y masiva de niños y niñas. Esta aptitud o idoneidad propia de las maestras fue contemplada bajo supuestos maternos esencialistas, que resaltaban la vocación de la mujer para dedicarse a la educación de los otros (aunque, efectivamente, las mujeres fueron elegidas como docentes por razones económicas: al no ser sustento de hogar los salarios podían ser no solo más bajos sino demorados e incluso nunca pagados).

En esta clave, 15 cartas escritas durante los años 1875 y 1879 por la primera directora del curso inicial del Normal de Rosario demuestran las deudas que el Ministerio solía tener con la docente, pero al mismo tiempo su descontento por no recibir la paga correspondiente. Así, el hallazgo de estas cartas posibilitó poner en jaque supuestos sobre la pasividad y obediencia femeninas, para reconsiderar el papel de la mujer a la hora de reclamar por sus derechos $y$, en ese mismo sentido, el modo de relacionarse con otros y con nuevos espacios de poder (varones jerárquicamente superiores). Más allá de que las mujeres fueran consideradas como propias del oficio docente por sus características domésticas naturales, esto resultó una nueva posibilidad para la esfera femenina de salir de sus casas e interactuar con el espacio público, negado por años.

De manera general, desde este trabajo se ha podido repensar el accionar de aquellos actores históricos que, por varias décadas, han sido silenciados por la historiografía argentina. Si bien se contaba con pequeñas huellas dejadas por la maestra, estas fueron trabajadas desde los límites, lo que permitió crear hipótesis sobre la participación de estas voces, individuales y singulares, que supieron romper con los esquemas de la sociedad escolar de fines del siglo XIX. 


\section{REFERENCIAS}

Barrancos, D. (2001). Inclusión/exclusión. Historia con mujeres. Buenos Aires: Fondo de Cultura Económica.

Carvalho, E. y Colovini, J. (2002). Colegio nacional de rosario: orígenes, fundación y primeros tiempos. Crónica documentada. Rosario: Asociación Ex Alumnos Colegio Nacional $N^{\circ} 1$ y Asociación Cooperadora Colegio Nacional №1.

Castillo Gómez, A. (2005). El mejor retrato de cada uno. La materialidad de la escritura epistolar en la sociedad hispana de los siglos XVI y XVII. Hispania, LXV/3 (221), 847-876.

Chambers, S. C. (2005). Cartas y Salones: mujeres que leen y escriben la nación en la Sudamérica del siglo XIX Araucaria. Revista Iberoamericana de Filosofía, Política y Humanidades, 7 (013), 77-106.

De Certeau, M. (2000). La invención de lo cotidiano. México: Cultura Libre.

De Certeau, M. (1974). L'opération historique. Le Goff, J. y Nora, P. (Dirs.) Faire de I'histoire. Tome I: Problèmes Nouveaux. París: Gallimard.

Fernández, S. y Caldo, P. (2013). La maestra y el museo. Rosario: El ombú bonsái.

Fraser, N. (1993). Repensar el ámbito público: una contribución a la crítica de la democracia realmente existente. Debate Feminista, 7 (4), 23-58.

Guha, R. (2002). Las voces de la historia y otros estudios subalternos. Barcelona: Crítica.

Lionetti, L. (2007). La misión política de la escuela pública: educar al ciudadano de la república (1870-1916). Buenos Aires: Miño y Dávila.

Morgade. G. (Comp.). (1997). Mujeres en la educación. Género y docencia en la Argentina 1870-1930. Buenos Aires: Miño y Dávila.

Rockwell, E. (1997). Hacer escuela, hacer estado: la educación posrevolucionaria vista desde Tlaxcala. México: Centro de Investigaciones y Estudios 
Superiores en Antropología Social (CIESAS) y Centro de Investigación y de Estudios Avanzados (Cinvestav).

Sarmiento, D. F. (2011) Educación popular. La Plata: Unipe Editorial Universitaria. Yannoulas, S. (1996). Educar: ¿una profesión de mujeres? La feminización del normalismo y la docencia (1870 - 1930). Buenos Aires: Kapeluz.

\section{Corpus documental consignado en el Archivo del Colegio Nacional N. 1}

Coolidge, I. (1875, 25 de mayo). [Carta a Enrique Corona Martínez]. Rosario, Argentina.

Coolidge, I. (1875, 10 de junio). [Carta a Enrique Corona Martínez]. Rosario, Argentina.

Coolidge, I. (1879, 25 de octubre). [Carta al Ministro de Justicia, Culto e Instrucción Pública, Dr. Don Miguel Goyena]. Rosario, Argentina.

Registro Nacional de la República Argentina (1877). [Contrato celebrado entre la Maestra Normal Isabel B. Coolidge y el Ministro Plenipotenciario de la República Argentina, Doctor Manuel R. García]. Rosario, Argentina. 